\title{
Liaoning Industrial Tourism and Cultural Resources Development
}

\author{
Shu Dong \\ Liaoning University of Media and Communication,110136, China
}

\begin{abstract}
Industrial tourism culture resources is a kind of new tourism concept, is also a kind of new way of tourism, as people material life gradually meet people for the pursuit of spiritual life more, so this kind of new form of tourism presents the vigorous development of form, as the old industrial base of liaoning province, the number of industrial enterprises with leading the country, At the same time, it also has the advantages of geographical location, resources, environment, tourist source market and so on to develop industrial cultural tourism. However, liaoning province's industrial cultural tourism started late, and has immature development, inflexibility of the market and other problems urgently need to be solved.
\end{abstract}

Keywords: Liaoning Province; Industrial Tourism; Cultural Resources; Countermeasure.

\section{Introduction}

At present the development of industrial tourism in liaoning province, and dug with certain cultural resources, such as shenyang aviation expo park has become a leader of the national industrial tourism demonstration pilot project of cultural resources, other industrial demonstration pilot project of tourism and cultural resources has become a national industrial tourism and cultural resources of famous destination, have achieved remarkable economic and social benefits. In order to promote the development of tourism and promote the development of enterprises, Anshan iron and steel industry tourism and cultural resources has developed into a set of tourism, accommodation, catering, entertainment as one of the comprehensive service function network system.

\section{SWOT Analysis of Liaoning Province's Industrial Tourism and Cultural Resources}

\subsection{Industrial Development Advantages}

(1) The historical background of industrial culture is long

Liaoning has many well-known industrial enterprises, such as Shenyang Shenyang Shenyang Shenyang Shenyang Shipyard, Dalian Anshan Iron and Steel, Benxi Bensteel, Fushun mines and so on. These industrial enterprises in Liaoning have played a decisive role in the country and the world, and their facilities and equipment are quite perfect.

(2) Rich industrial tourism and cultural resources

More industrial resources in liaoning province, ranked front in the provinces and cities all over the country, too, more or less to every city in liaoning province has the industrial resources, including aircraft ship, non-ferrous metals, non-metallic resources such as coal mining, and these resources have certain reference and development value, develop the cultural resources in the industry, It can not only relieve the pressure of the transformation of resource-based cities in our province, but also provide strong resources for the development of industrial tourism and cultural resources.

(3) Complete industrial and cultural infrastructure

At present, there are nearly 800 star-rated hotels at liaoning nearly thousand travel agency, and infrastructure construction of liaoning province is relatively perfect, also meet the demand of increasing of tourism, in addition, relatively perfect in liaoning traffic, communication system, shenyang has six railway and 29 branch lines, density and double-track railways ranking first in the country. Liaoning also has the only seaport in northeast China, shenyang Taoxian International Airport, Dalian Zhoushuizi International Airport, chaoyang, Dandong, Jinzhou and other regional 
airports, which have opened 127 domestic air routes and 38 international and regional air routes. Nowadays, it has formed a perfect three-dimensional cross-transportation system of land, sea and air, which provides great convenience for tourists to travel in a short time.

\subsection{Disadvantages of Industrial Development}

At present, the idea of developing industrial tourism cultural resources in Liaoning is still very conservative, and the concept is still very backward. The main reasons are as follows: Firstly, because of the geographical location, liaoning people's thoughts are relatively conservative. Liaoning, located in Guanzhong, has not had enough influence on foreign cultures. Because there are many companies that develop industrial tourism is the destruction of industrial enterprises, and the effect of the development of no confidence, but also for the development of the enthusiasm is not high, so the effect of the industrial tourism culture resources in liaoning province is difficult to immediately, the old ideas will inevitably hinder the development of industrial tourism, the cultural resources is not found, Liaoning unique industrial resources can not be fully utilized.

Single industrial cultural derivatives

Li Shumin put forward that the integration of tourism industry is the product of tourism and other industries forming a new industrial value chain and tourism symbiosis through the selection and extension of value chain. The development of liaoning industrial tourism culture resources products content is relatively simple, mainly displays in: first of all, many industrial companies limit their tourism activities in the limited travel channel or area, so as not to affect the production, the limitation of this access scenario that stay in the company of tourists it is difficult to be interested in a very short time, leading to most visitors feel constrained; Second, the development of liaoning's industrial tourism and cultural resources is relatively simple. The vast majority of this single form attracts professionals, which impedes the goal of popularizing industrial tourism cultural resources; Third, tourism products launched by similar industrial enterprises are often similar and lack of characteristics.

\section{Industrial Development Opportunities}

\subsection{Policy Opportunities}

History has proved that every major strategic measure introduced into the country will strongly promote the historical process. At present, the national revitalization of the northeast old industrial base, the development of northeast manufacturing environment and new policies, will also bring a rare policy opportunity for the development of liaoning industrial tourism and cultural resources.

\subsection{Market Opportunities}

History has proved that every major strategic measure introduced into the country will strongly promote the historical process. At present, the national revitalization of the northeast old industrial base, the development of northeast manufacturing environment and new policies, will also bring a rare policy opportunity for the development of liaoning industrial tourism and cultural resources.

\section{Threats to Industrial Development}

\subsection{Industry Competition Threat}

Developing industrial tourism in liaoning province in northeast China has two big strong competitors, heilongjiang and jilin, the two provinces in the same way as a major industrial province its development momentum over liaoning, it has a huge pressure on developing industrial tourism in our province, not only so, fujian association of foreign languages and many of the modern industrial city are also actively developing industrial tourism, And the cultural resources have also been relatively perfect development. For example, Baosteel, Jiangnan Shipyard and Volkswagen in 
Shanghai are all planned to be included in the list of industrial tourism and cultural resources, and these enterprises are also highly famous, which will surely compete with Liaoning Province.

\subsection{Threat of Competition from Different Products}

Liaoning industrial tourism culture resources, so from the attraction and experience, is not high, now with more tourists want to see a variety of products, but enough of the tourism product development in liaoning province, the product has the oneness, compared with other areas of diversification of industrial tourism and cultural products, the development of our province is not enough, lack of competitiveness, These tourism products must be the main competitors in the development of industrial tourism cultural resources.

\section{Fifth, Liaoning Province Industrial Tourism Cultural Resources Development Countermeasures}

\subsection{Industrial Tourism and Cultural Resources should be Integrated in Many Ways}

Industrial tourism is a new thing slowly formed by industry and tourism after long-term run-in and development, so it has both the characteristics of industry and the advantages of tourism, with higher value, more functions, with the increase of market demand, will give it new vitality. For industrial enterprises, after the emergence of resource integration, they should constantly adjust their internal structure and optimize their resource allocation, and combine their business processes by integrating various value chains, so as to create tourism products with Liaoning characteristics.

\subsection{Develop Industrial Tourism Products with Liaoning Characteristics}

The cultural resources of liaoning province is various, so can give full play to the local features developed in liaoning have the characteristics of liaoning industrial tourism cultural products, both to promote the development of the industry can also promote the progress of tourism industry, based on the development of characteristic industry in liaoning province tourism products production base, large scale production, to build brand in liaoning industrial tourism cultural products, Let the arrival of tourists get the unique experience of industrial tourism, for example, the two kinds of fushun west open pit specialty - jet and amber, the two substances are rare minerals, to the brand management, establish a belongs to the liaoning industrial tourism culture brand, to gradually improve the influence, it will help liaoning industrial tourism culture resources have a positive significance.

\section{Conclusion}

Industrial tourism is a new form of tourism, as a branch of the tourism industry has developed rapidly in our country, which stimulates the development of the our country economy, but the liaoning industrial tourism development is not mature, the relative lack of effective theoretical guidance, so need through analyzing related researchers more, of course there are many kinds of industrial tourism in way, The use of cultural resources for development is only one of the feasible means, which can be implemented and utilized through perfect development.

In this article, through the SWOT analysis on the industrial tourism culture resources in liaoning province development strengths, weaknesses, opportunities and threats to carry on the simple analysis, it can be seen that although large industrial culture resources in liaoning province, but its development still has limitations, and did not play the advantage of the same industry, Therefore, it is the core to find the way suitable for the development of Liaoning Province. 


\section{References}

[1] Ha Jing, QU Wei. Industrial history and Industrial building Remains in Shenyang [J] Beijing Planning and Construction, 2019 (1) : 37-42.

[2] Zhang Lifeng, Lu Lei. Study on dynamic Mechanism and Countermeasures of Dalian industrial heritage tourism Development [J]. Tourism Economy2010, 11:167-169.

[3] Wen J J. Discussion on the problems of developing Industrial tourism in Liaoning province [J]. Science and Technology Innovation Review, 2019(7): 125-128.

[4] Yang Qingxian. Comparative advantage analysis of hanzhong tourism development. Ecological Economy, 2010, 8:162-164.

[5] Han Fuwen, Wang Fang. Construction of industrial Characteristic Cultural city from the perspective of Industrial Heritage Protection -- A case study of Liaoning Industrial city[J]. Economic Geography, 2013 (6).

[6] Liang K, Du J C. Research on the development mode of modern industrial tourism from the perspective of industry convergence [J]. World Geography Research.2015(03).

[7] Feng Shanshan, Chang Jiang. Mining heritage routes from the perspective of regional Cooperation: From "island protection" to "Network development". Chinese Landscape Architecture.2012 (8): 11-17. 